\title{
A relação entre poética e sistema literário em André Lefevere
}

Thiago Mattos*

\section{André Lefevere nos Estudos da Tradução}

Os Estudos da Tradução formam uma área multidisciplinar atravessada por saberes advindos dos mais diversos lugares: comunicação, história, linguística, teoria literária, semiótica etc. Enquanto algumas correntes aproximamse de estudos de base predominantemente linguística, outras se aproximam dos estudos histórico-culturais.

André Lefevere é um dos mais significativos representantes da vertente dos Estudos da Tradução que privilegia o cultural, o histórico e o ideológico. Mas, como é fácil supor, não está sozinho nesse tipo de abordagem. Como mostra Milton (2010, p. 207), dois grupos estão mais fortemente identificados com a abordagem de base culturalista: de um lado, pesquisadores originados dos Países Baixos e de Israel (Lefevere no primeiro caso; EvenZohar e Gideon Toury no segundo); e de outro, pesquisadores funcionalistas ligados à Universidade de Göttingen, na Alemanha. O que une esses autores é, generalizando, a concepção não essencialista do texto de partida e do texto de chegada: enquanto Lefevere, Even-Zohar e Toury olham para a literatura como um sistema de variadas relações dinâmicas, os teóricos funcionalistas olham para a função que o texto traduzido (na maior parte das vezes um texto não literário) desempenha no sistema de chegada.

Quais são os caminhos percorridos por determinada poética no sistema literário em que está inserida? Quais são as forças que estão em jogo para a cristalização, promoção ou apagamento dessa poética? A obra de

\footnotetext{
* Doutorando do programa de Estudos Linguísticos, Literários e Tradutológicos do Francês na Universidade de São Paulo.
} 
Lefevere (que, como veremos, não deixa de apresentar pontos problemáticos) torna possível, senão respostas definitivas, ao menos reflexões pertinentes para esse tipo de pergunta. Neste artigo, portanto, procuraremos iluminar a relação tensa e não essencialista entre poética e sistema literário.

\section{Duas noções-chave: manipulação e sistema literário}

Lefevere defende que tradução é reescritura. E, sendo reescritura, é também manipulação: "toda reescritura, qualquer que seja sua intenção, reflete uma certa ideologia e uma poética e, como tal, manipula a literatura para que ela funcione dentro de uma sociedade determinada e de uma forma determinada" (Lefevere, 2007, p. 11). A tradução não é um processo de substituição direta, mas de reescritura, e, como toda escritura, uma reescritura está também inscrita em certas condicionantes históricas, ideológicas e culturais. Pode-se dizer que a reescritura-tradução é uma manipulação na medida em que age procurando fazer com que essa reescritura-tradução corresponda a determinados preceitos e padrões poetológicos e ideológicos. A manipulação pode tanto desempenhar papel fundamental no desenvolvimento de uma literatura, introduzindo novos gêneros, fomentando novos modos de fazer literário, quanto restringir, distorcer ou mesmo apagar autores, obras e poéticas.

A tradução é o tipo de reescritura mais produtiva, isto é, o tipo de reescritura capaz de mais duradouramente manipular a literatura. Isso porque, como explica Lefevere, leitores não profissionais leem, ao menos hoje, mais reescrituras do que escrituras propriamente ditas, de onde o papel central da tradução:

\begin{abstract}
[reescritores são tão] corresponsáveis, em igual ou maior proporção, que os escritores, pela recepção geral e pela sobrevivência de obras literárias entre leitores não profissionais, que constituem a grande maioria dos leitores em nossa cultura globalizada (Lefevere, 2007, p. 13).
\end{abstract}

Está aí o primeiro mérito do trabalho de Lefevere: colocar o tradutor, para a promoção ou rejeição de uma poética, ao lado (ou, dependendo do 
caso, até acima) do escritor. Como se, parafraseando uma citação de Saramago que já se tornou clássica entre tradutores (e guardadas suas evidentes diferenças), a literatura nacional pertencesse aos escritores, enquanto a literatura mundial pertencesse aos tradutores.

Contudo, Lefevere não trabalha com noções de "literatura nacional" ou "literatura mundial": fala, na verdade, em sistema literário, noção que abriga de maneira dinâmica uma série de relações, tensões e contradições que estão continuamente em jogo nessa rede de escrituras e reescrituras, escritores e reescritores que forma e conforma o sistema literário. A vantagem da noção de sistema, argumenta Lefevere (2007, p. 25), deve-se à sua dimensão pedagógica, na medida em que ajuda a tornar visível e relativamente regular algo que não se dá na natureza, observável e mensurável, mas na prática humana. A literatura é uma práxis, não um fenômeno natural. Como tal, a ideia de sistema permite delimitarmos com mais segurança as fronteiras desse objeto (movente) e identificarmos com mais nitidez as relações, dinâmicas e funcionamentos que estão aí em jogo. Além disso, a noção de sistema garante uma abordagem não etnocentrista, permitindo que se pense a literatura como um subsistema que integra um conjunto complexo de sistemas que formam a cultura. Lefevere entende, nesse sentido, que a literatura é um sistema artificial (já que é práxis) formado por agentes humanos que leem, escrevem e reescrevem textos. Diferentemente da concepção estruturalista, esse sistema não está isolado em si mesmo, mas, como já destacamos, integra-se a um conjunto dinâmico de outros sistemas (ciências, sociologia, filosofia etc.) igualmente fundados na prática humana e social. Essas práticas que se dão no interior do sistema literário são, portanto, de suma importância para Lefevere: são elas que, inscritas nessa ou naquela ideologia, submetidas a essa ou aquela corrente poetológica, colocam o sistema em movimento, operam canonizações, rejeições, apagamentos, distorções.

\section{Outras noções-chave: ideologia e correntes poetológicas}

Tocamos, assim, em outras duas noções fundamentais para compreender a relação entre poética e sistema literário: a noção de ideologia e a noção daquilo que Lefevere chama de correntes poetológicas. 
Recuperando Jameson, Lefevere entende a ideologia como um "gradeado de forma, convenção e crença, que ordena nossas ações" (Jameson apud Lefevere, 2007, p. 35). A ideologia seria um complexo de modos convencionados de agir. A ideia de ação desempenha um papel importante na ideologia, que deixa de ser um abstrato conjunto de ideias, teorias etc., como se poderia pensar a partir de certo sentido geral, e passa a ser uma $a c ̧ a \tilde{o}$ condicionada a convenções, crenças, modos de significar o real.

No entanto, a reescritura e a manipulação não se encerram somente em condicionantes ideológicas: "se algumas reescrituras são inspiradas por motivações ideológicas, ou produzidas sob restrições ideológicas, [...] outras reescrituras são inspiradas por motivações poetológicas" (Lefevere, 2007, p. 22). Essas motivações poetológicas dizem respeito às poéticas dominantes em cada sistema literário, a depender do momento histórico. Essas poéticas, uma vez ocupando um espaço dominante nesse sistema, procuram se mostrar como não históricas e perfeitamente estáveis, como se não houvesse nem um passado legítimo nem um futuro possível fora dos seus modos de fazer poético, imobilizando e controlando a própria dinâmica do sistema.

Um sistema literário apresenta dois fatores simultâneos fundamentais para certa estabilidade, ou efeito de estabilidade. O primeiro são os reescritores, isto é, os profissionais que reescrevem textos: críticos, resenhistas, editores, tradutores etc. O segundo diz respeito ao mecenato: agentes públicos ou privados, instituições de ensino, academias etc. que incentivam (ou barram) autores, obras e, num sentido mais amplo, poéticas. Ambos, reescritores e mecenato, estão inscritos tanto em correntes ideológicas quanto em correntes poetológicas. $\mathrm{O}$ reescritor, e aqui levaremos em conta especificamente a figura do tradutor, é um sujeito ideológico, isto é, está submetido à ideologia e à história. Não só isso: reescritores reescrevem textos a partir de inscrições ideológicas e a partir também de uma identificação maior ou menor com determinadas correntes poetológicas. Reescritores, assim como escritores e leitores, não são, no entanto, sujeitos onipotentes: o mecenato é um fator primordial na organização das relações desse sistema. Como explica Lefevere (2007, p. 34), o mecenato é algo próximo dos poderes, podendo incentivar ou impedir "a leitura, escritura e reescritura de literatura" (Lefevere, 2007, p. 34). O exemplo clássico do mecenato costuma ser Caio Mecenas, ou 
a família de Médici no Renascimento, mas contemporaneamente podemos pensar também (e principalmente) em outros tipos de mecenato, que agem, senão na própria produção de escrituras e reescrituras, ao menos na sua distribuição: revistas de literatura, estabelecimentos de ensino, editoras, instituições culturais, academias (pensemos, para não nos distanciarmos do sistema literário brasileiro, no caso da Academia Brasileira de Letras, seus prêmios literários, sua autoridade para opinar sobre querelas literárias e linguísticas etc.). O mecenato tem não apenas um componente ideológico, mas também econômico (sabemos que a comercialização de direitos autorais, por exemplo, gera consideráveis ganhos) e de status, isto é, o mecenato envolve também certo "estilo de vida" próprio de um grupo de prestígio intelectual, econômico etc. Via de regra, o mecenato é o responsável direto por correntes ideológicas e poetológicas dominantes no sistema literário daquele momento, aproximando-se em certa medida daquilo que explica Bourdieu sobre a cultura dita erudita:

\begin{abstract}
o campo de produção erudita tende a produzir ele mesmo suas normas de produção e os critérios de avaliação de seus produtos e obedece à lei fundamental da concorrência pelo reconhecimento propriamente cultural concedido pelo grupo de pares que são, ao mesmo tempo, clientes privilegiados e concorrentes (Bourdieu, 1974, p. 105).
\end{abstract}

\title{
Historicidade, reescritura e manipulação da fama literária
}

A exposição anterior nos leva, finalmente, à noção de historicidade, nem sempre mencionada explicitamente por Lefevere. Podemos pensar que é ela que resume e articula as concepções que Lefevere desenvolve sobre reescritura, sistema literário e manipulação. Para além do cultural, das situações imediatas de produção e distribuição de reescrituras, o que está em jogo no trabalho de Lefevere é a historicidade, que dá conta tanto da dimensão ideológica quanto da dimensão poetológica dos processos de reescritura e manipulação num determinado sistema literário:

\footnotetext{
o processo que resulta na aceitação ou rejeição, canonização ou não canonização de trabalhos literários não é dominado pela moda, mas por fatores bastante concretos que são relativamente fáceis de discernir assim que se decide procurar por eles, isto é, assim que se evita a interpretação como o
} 
fundamento dos estudos literários e se começa a enfrentar questões como o poder, a ideologia, a instituição e a manipulação (Lefevere, 2007, p. 14).

Textos não são intrinsecamente bons ou ruins, não são essencialmente superiores (canônicos) ou inferiores, mas assim são vistos, significados, reproduzidos, distribuídos, traduzidos e reescritos (ou, finalmente, refratados) conforme o trabalho de sujeitos e instituições inscritos em determinadas formações ideológicas e em determinadas correntes poetológicas.

Para ficarmos tanto no sistema literário brasileiro quanto na perspectiva da tradução, pensemos brevemente no exemplo das (re)traduções brasileiras das Fleurs du mal, de Baudelaire. Faleiros (2014, 2011, 2010) mostra como predomina nas traduções brasileiras uma concepção poetológica que privilegia a métrica e a rima, em detrimento do prosaísmo sintático e da composição imagética do poeta francês. Tal concepção, que se torna dominante na tradução de poesia no Brasil, remonta a Guilherme de Almeida, passa por Haroldo de Campos e alcança tradutores contemporâneos, como Ivan Junqueira (ele próprio, aliás, tradutor das Fleurs du mal). Nessa corrente poetológica de tradução de poesia, comparece, em maior ou menor grau, a convicção de que o poético reside majoritariamente na dimensão significante: correspondência métrica, reconstrução rigorosa de rimas etc. Sacrificam-se, se necessário, ordenações sintáticas; alteram-se elementos de ordem semântica, imagética ou retórica, como o caso sempre lembrado da tradução de Ivan Junqueira do poema "Correspondances", das Fleurs du mal, que transforma, em nome da rigorosa correspondência formal, "florestas de símbolos" [forêts de symboles] em "bosque de segredos".

Não estamos com isso defendendo este ou aquele modo de traduzir poesia. Estamos apontando para o fato de que diferentes tradutores inscrevem-se em diferentes correntes poetológicas, reescrevendo textos e autores a partir de lugares distintos, para corresponder em maior ou menor grau a correntes ideológicas e poetológicas que dominam, naquele momento, o sistema literário em questão. Esse modo de traduzir poesia (e de traduzir especificamente poemas de forma fixa) tem impactos consideráveis, por exemplo, na imagem que se cria de Baudelaire no sistema literário brasileiro. Não raro vemos em manuais de literatura para o ensino médio (em parte em razão 
dessas traduções que apagam a dimensão prosaica de Baudelaire, em parte por conta de certa crítica que hiperdimensiona a ideia de "poesia pela poesia" que começa a surgir com o poeta francês) a presença de Baudelaire como poeta parnasiano por excelência, que teria servido de base para o próprio parnasianismo brasileiro.

Como já bem disse Lefevere,

\begin{abstract}
reescritores criaram imagens de um escritor, de uma obra, de um período, de um gênero e, às vezes, de toda uma literatura. Essas imagens existiam ao lado das originais com as quais eles competiam, mas as imagens sempre tenderam a alcançar mais pessoas do que a original correspondente e, assim, certamente o fazem hoje (Lefevere, 2007, p. 18-19).
\end{abstract}

Daí, aliás, a relevância e a centralidade da retradução: retraduzimos para dar a ver, de outro lugar e de outra maneira, um autor, um texto, uma poética, significando-o de outra maneira no sistema literário em questão. Para tanto, o reescritor inscreve-se em outra corrente poetológica, dominante ou não naquele sistema literário em questão, sendo capaz de reescrever e ressignificar o texto de outra maneira, por outros caminhos. Para continuarmos com o caso das Fleurs du mal, pensemos na proposta de Faleiros de traduzir Baudelaire sem medida (Faleiros, 2011), evidenciando aspectos (imagens, sintaxe prosaica, recursos retóricos etc.) que os tradutores anteriores foram obrigados a sacrificar a fim de dar conta das exigências da corrente poetológica e ideológica a que estavam vinculados.

\title{
Reescrevendo e manipulando André Lefevere
}

Lefevere parece trabalhar ocasionalmente a partir de uma perspectiva maniqueísta da ideologia, isto é, como se sujeitos reescritores e instituições inseridas no mecenato conscientemente manipulassem (termo que já traz certo aspecto intencional e consciente) reescrituras, imagens de textos, autores etc.

Produzindo traduções, histórias da literatura ou suas próprias compilações mais compactas, obras de referência, antologias, críticas ou edições, reescritores adaptam, manipulam até um certo ponto os originais com os quais 
eles trabalham, normalmente para adequá-los à corrente, ou a uma das correntes ideológicas ou poetológicas dominantes de sua época (Lefevere, 2007, p. 23)

Subsiste na noção de ideologia de Lefevere um aspecto intencional: reescritores manipulam conscientemente, intencionalmente, para adequar textos, autores etc. a correntes ideológicas e poetológicas dominantes naquele momento do sistema literário. Essa hipótese pode trazer três problemas principais: 1) ignoram-se os diversos projetos tradutórios que pretendem exatamente romper com correntes dominantes. É o caso do projeto tradutório das Fleurs du mal elaborado por Faleiros, o projeto tradutório das Fleurs du mal de Gabriela Llansol em Portugal, o projeto tradutório do Guardador de rebanhos da canadense Eirin Moure etc. Em todos esses casos, pretende-se deliberadamente tensionar, via tradução, correntes ideológicas e poetológicas dominantes no sistema literário daquele momento, ressignificando certo autor, certo texto, certa poética. 2) Encara-se a inscrição ideológica e poetológica de uma perspectiva consciente e puramente intencional. Dito de outro modo, Lefevere parte do princípio de que a inscrição ideológica e poetológica se dá de maneira consciente e passiva, a fim de adequar textos e autores a correntes dominantes. Para problematizar sua posição, sem no entanto negar seus princípios e posições básicos, valeria a pena pensarmos na presença de uma noção de sujeito na teoria de Lefevere. Para tanto, poderíamos recorrer a autores que veem a ideologia como constitutiva do próprio sujeito, e portanto "onipresente", como Michel Pêcheux (1995) e Louis Althusser (1999), que destacam o caráter inconsciente e não intencional da ideologia, ou seja, o sujeito, atravessado duplamente pelo inconsciente e pelo ideológico, é interpelado ideologicamente (Althusser, 1999), ainda que seu discurso tente dar a ilusão de ser a fonte do que diz. 3) Ao deixar em aberto esse espaço entre o poetológico e o ideológico, Lefevere pode ocasionalmente dar a entender que a ideologia tem um fora, isto é, existe algo exterior à ideologia. Seria possível, nesse sentido, reescrever a partir de intenções puramente poetológicas, e não ideológicas. Mas nos parece possível considerar que correntes poetológicas, que trazem consigo determinada visão so- 
bre a literatura, ou o que deve ser considerado literatura, são também correntes ideológicas, ou seja, têm uma forte dimensão ideológica em si mesmas. Faltaria, portanto, uma reflexão teórica que desse conta justamente dessa articulação entre poetológico e ideológico: afinal, será mesmo possível pensar correntes poetológicas sem estarem inscritas em formações ideológicas mais amplas, gerais, estruturais e estruturantes? Responder a essas perguntas nos conduziria a outro artigo, com outros objetivos. Por ora, deixemos tais questões em seu estado de abertura.

Um dos grandes méritos da teoria de Lefevere, e que pode ser analisado independentemente dos problemas que acabamos de destacar, diz respeito ao lugar de destaque dado à figura do tradutor - e do reescritor de modo geral: críticos, resenhistas, editores etc. tornam-se figuras fundamentais no sistema literário, tão influentes quanto o próprio autor, que depende diretamente dessas diversas instâncias do sistema. Independentemente de condicionantes ideológicas e poetológicas, o tradutor é essencial para a constituição de um cânone em determinado sistema literário, o que nos faz pensar, até certo ponto, no trabalho dos concretos. Haroldo de Campos, assim como Lefevere, mas em posições consideravelmente distintas, também promove o tradutor a um lugar central no sistema literário. Ancorando-se em Jakobson (transposição criativa) e partindo da ideia de que a equivalência total é, a rigor, impossível, Campos defende que a única saída possível é a transcriação, a criação poética de um novo texto, a instauração, via tradutor, de um novo poema na língua de chegada. Esses poemas "serão diferentes enquanto linguagem, mas, como corpos isomorfos, cristalizar-se-ão dentro de um mesmo sistema" (Campos apud Faleiros, 2012, p. 20). Para Campos, a tradução é não somente criação literária (ou transcriação, para retomar a terminologia dos concretos), mas também crítica, já que o tradutor tenta antecipar a criação literária, coloca-se em posição de vanguarda, ordena a produção literária que já foi feita, elimina repetições e "configura uma tradição viva" (Faleiros, 2012, p. 21). O tradutor ocupa, portanto, um lugar duplo: o do criador e o do crítico, guiando a criação, dando nova vida ao passado literário (está aí a base poundiana de Campos, que convive com sua base jakobsoniana) e, numa posição radical, usurpando o próprio lugar do autor no sistema literário. Perceba-se que Campos também concebe ao tradutor 
uma posição central, capaz de intervir diretamente sobre o sistema, canonizando, apagando, organizando; capaz, em última análise, de criar literatura nesse sistema. Apesar disso, é evidente que Campos e Lefevere ocupam lugares distintos. Para Lefevere, os tradutores, como reescritores submetidos (ou que voluntariamente assim se submetem) a condicionantes ideológicas e poetológicas, criam imagens de um autor, de um texto, de uma época, de uma poética; canonizam, apagam, rejeitam. Para Campos, o tradutor é criador, funda texto, é capaz de antecipar vanguardas e de organizar a tradição poética, dando novos ares ao passado e usurpando o próprio lugar desses autores no sistema literário. Enquanto em Lefevere está em jogo o ato tradutório como ato essencialmente histórico e ideológico, em Campos está em jogo o ato tradutório como ato altamente criativo, capaz de fazer e ser literatura; está em jogo, finalmente, a criação poética, a transcriação.

Além disso, Paulo Henriques Britto também nos ajuda a identificar outras contradições (ou ao menos outros problemas) nos trabalhos de cada um desses autores. Britto (2012) mostra que Lefevere, apesar de colocar no centro do debate a ideia de que a tradução é uma reescritura, estando, portanto, submetida ao jogo ideológico e poetológico do sistema literário em um determinado momento, sua concepção de tradução poética reserva algo de contraditoriamente essencialista e mesmo normativo. Ao comentar as traduções dos poemas de Catulo para o inglês, Lefevere termina por identificar problemas em todas elas, concluindo que, se uma tradução de poema não é perfeita, não pode sequer ser vista como tradução literária (Britto, 2012, p. 124-125). Quanto a Haroldo de Campos, Britto identifica em suas reflexões teóricas (e mesmo em sua prática tradutória, que de fato não pode ser separada do seu trabalho teórico) uma hybris que hiperdimensiona o tradutor e o fazer tradutório, considerando criação literária o que, na visão de Britto, não é criação literária, mas simplesmente (se assim podemos dizer, já que a tradução nada tem de simples) tradução.

\section{Conclusão}

Ao expor e analisar o pensamento de Lefevere, procuramos destacar a relação entre poética e sistema literário, recorrendo, para isso, a uma perspectiva 
que veja essa relação a partir de uma dimensão histórica e ideológica. Traduzimos/reescrevemos para "adequar o texto a uma poética dominante" (Lefevere, 2007, p. 40). Isso é uma possibilidade. Mas também cabe a pergunta: não seria possível reescrever para ressignificar um autor rompendo com a formação ideológica e com a corrente peotológica dominantes no sistema literário? Teria a poética dominante todo esse poder de coerção sobre todos os tradutores, como por vezes dá a entender Lefevere? Não seria possível reescrever a partir de uma outra inscrição ideológica? Não afirmamos com isso que seja possível reescrever fora de ideologias e correntes poetológicas, afirmamos que a reescritura e a manipulação podem se colocar eventualmente no lado oposto ao do que naquele momento domina, conforma e tenta guiar o sistema literário.

O que está em jogo é, de todo modo, a questão da historicidade mesma da tradução: modos de ler e dizer de outro modo, a partir de momentos e lugares distintos, em inscrições ideológicas e poetológicas diversas (e por vezes adversas).

Lefevere, como Campos, coloca o tradutor num lugar central, capaz de formar cânones, rejeitar nomes, revitalizar épocas. Diferentemente de Lefevere, contudo, importa para Campos não a tradução na sua dimensão histórico-ideológica, mas a tradução como criação literária, como transcriação. Britto, como mostramos, é um bom problematizador de ambos os autores. No entanto, é evidente que Britto tem também ele seu próprio entendimento de tradução e está, como Lefevere e Campos, historicamente situado, estabelecendo relações (ativas e dinâmicas) com ideologias, correntes poetológicas, modos de entender o fazer tradutório. Está, tanto quanto Lefevere e Campos, submetido à própria historicidade que atravessa o sistema literário. No limite, poderíamos dizer, na esteira de Lefevere, que teóricos e críticos da tradução, tanto quanto tradutores/reescritores, ocupam determinada posição no sistema literário, promovendo entendimentos do que pode e não pode ser considerado tradução, do que deve ser ou não deve ser uma boa tradução, do que, finalmente, é (ou deva ser) o tradutor, a tradução e a poética do traduzir. 


\section{Referências}

ALTHUSSER, Louis. Sobre a reprodução. Petrópolis: Vozes, 1999.

BOURDIEU, Pierre. A economia das trocas simbólicas. São Paulo: Perspectiva, 1974.

BRITTO, Paulo Henriques. A tradução literária. Rio de Janeiro: Civilização Brasileira, 2012.

CAMPOS, Haroldo de. Transcriação. Org. Marcelo Tápia e Thelma Médici Nóbrega. São Paulo: Perspectiva, 2013.

FALEIROS, Álvaro. Traduzir o poema. São Paulo: Ateliê Editorial, 2012.

Bendito Baudelaire. Teresa (USP), v. 14, p. 43-52, 2014. Disponível em: $<$ http://www.revistas.usp.br/teresa/article/view/98591> Acesso em: 15 de agosto de 2015.

. As Flores do Mal sem medida: por uma retradução de Charles Baudelaire. Revista Brasileira de Literatura Comparada, v. 19, p. 145-156, 2011. Disponível em: < http://www.abralic.org.br/downloads/revistas/1415577858.pdf> Acesso em: 9 de agosto de 2015.

. Maria Gabriela Llansol retradutora de Charles Baudelaire. Cadernos de Tradução (UFSC), v. 25, p. 113-126, 2010. Disponível em: < https://periodicos.ufsc.br/index.php/traducao/article/download/2175-

7968.2010v1n25p113/13960> Acesso em: 9 de agosto de 2015.

LEFEVERE, André. Tradução, reescrita e manipulação da fama literária. Trad. Claudia Matos Seligmann. Bauru: EDUSC, 2007.

Mother Courage's Cucumbers: text, system and refraction in theory of literature. In: VENUTI, Lawrence. The translation studies reader. London and New York: Routledge, 2000.

MILTON, John. Tradução: teoria e prática. São Paulo: Martins Fontes, 2010. PÊCHEUX, Michel. Semântica e discurso: uma crítica à afirmação do óbvio. Trad. Eni Pulcinelli Orlandi, Lorenço Chacon J. Filho, Manoel Luiz Gonçalves Corrêa e Silvana M. Serrani. Campinas: Editora da Unicamp, 1995.

Resumo: Partindo de André Lefevere, estabeleceremos uma relação entre as noções de poética e sistema literário, utilizando quatro noções-chave: sistema literário, manipulação, ideologia e correntes poetológicas. Defendemos, a partir daí, que a historicidade atravessa essas noções, estruturando 
tal relação. A título de exemplo, recorremos às (re)traduções brasileiras das Fleurs du mal (Baudelaire), ilustrando de que maneira correntes poetológicas dominantes determinam não somente o que traduzir em um sistema literário, mas principalmente como traduzir. Concluímos apontando pontos problemáticos (e possíveis releituras) do trabalho de Lefevere.

Palavras-chave: André Lefevere; Sistema literário; Poética; Manipulação; Correntes poetológicas

Résumé: À partir d'André Lefevere, on établit un rapport entre poétique et système littéraire. Pour cela, on utilise quatre notions fondamentales : système littéraire, manipulation, idéologie et courants poétiques. Nous soutenons que l'historicité traverse ces notions et structure ce rapport. À titre d'exemple, nous utilisons le cas des (re)traductions brésiliennes des Fleurs $d u$ mal, afin de montrer que les courants poétiques majoritaires déterminent non seulement ce que l'on traduit dans un système littéraire, mais aussi comment on traduit. À la fin, on expose les points problématiques (et leurs relectures possibles) du travail de Lefevere.

Mots-clés: André Lefevere; Système littéraire; Poétique; Manipulation; Courants poétiques 